\title{
Composição química e valores de energia metabolizável de alimentos protéicos determinados com frangos de corte em diferentes idades
}

\author{
Gladstone Brumano1, Paulo Cezar Gomes², Luiz Fernando Teixeira Albino², Horacio Santiago \\ Rostagno $^{2}$, Rafaela Antônia Ramos Generoso ${ }^{3}$, Marlene Schmidt ${ }^{1}$
}

\footnotetext{
1 Doutorando em Zootecnia, DZO, UFV, Viçosa - MG.

2 Departamento de Zootecnia, DZO, UFV, Viçosa - MG.

${ }^{3}$ Mestrando em Zootecnia, DZO, UFV, Viçosa - MG.
}

RESUMO - Objetivou-se determinar a composição química e os valores de energia metabolizável de dez alimentos protéicos com frangos de corte em idades diferentes. Para determinar os valores de energia metabolizável aparente (EMA) e aparente corrigida (EMAn), utilizou-se o método tradicional de coleta total de excretas, com pintos de corte machos de 21 a 31 (primeiro período) e de 41 a 50 (segundo período) dias de idade, em um delineamento experimental inteiramente casualizado, com 10 tratamentos, seis repetições e seis e quatro aves por unidade experimental para o primeiro e o segundo período, respectivamente. Os alimentos estudados foram: farelo de algodão, farelo de glúten de milho, concentrado protéico de soja, duas farinhas de carne e ossos, farinha de peixe, farinha de vísceras de aves de alto teor de gordura, dois plasmas sangüíneos e hemácias. Os valores de EMAn ( $\mathrm{kcal} / \mathrm{kg}$ ), na matéria natural, no primeiro e segundo períodos, foram, respectivamente, 1.963 e 2.461 para o farelo de algodão; 3.608 e 4.013 para o glúten de milho; 2.043 e 2.155 para o concentrado protéico de soja; 1.249 e 1.573 para a farinha de carne e ossos $36 \%$; 1.391 e 1.766 para a farinha de carne e ossos $45 \%$; 3.055 e 3.077 para a farinha de peixe; 2.990 e 3.172 para a farinha de vísceras de aves de alto teor de gordura; 2.673 e 2.730 para o plasma sangüíneo $70 \%$; 3.027 e 3.704 para o plasma sangüíneo $78 \%$; e 2.834 e 3.256 para as hemácias. Os valores de EMA e EMAn de todos os alimentos obtidos no segundo período experimental foram superiores aos do primeiro período.

Palavras-chave: composição química, energia metabolizável, frangos de corte

\section{Chemical composition and metabolizable energy values of protein feedstuffs to broilers at different ages}

\begin{abstract}
ABSTRAT - The chemical composition and the metabolizable energy values of ten protein feedstuffs fed to broilers at different ages were evaluated. The traditional method of total feces collection was used to determine the values of apparent metabolizable energy (AME) and apparent metabolizable energy corrected by nitrogen (AMEn), in male broilers in the periods from 21 to 30 (first period) and from 41 to 50 (second period) days of age. The experiment was analyzed as a complete randomized design with 10 treatments, six replicates and six (first trial) and four poultry (second trial) per pen. The following feedstuffs were evaluated: cottonseed meal, corn gluten meal, soybean protein concentrate, two meat and bone meals, fish meal, full fat poultry by-product meal, two spray-dried plasma and erythrocytes. The AMEn ( $\mathrm{kcal} / \mathrm{kg}$ ) values on as-fed basis in the first and second experimental periods were as follows: cottonseed meal, 1,963 and 2,461; corn gluten meal, 3,608 and 4,013; soybean protein concentrate, 2,043 and 2,155; meat and bone meal 36\%, 1,249 and 1,573; meat and bone meal 45\%, 1,391 and 1,766; fish meal, 3,055 and 3,077; full fat poultry by-product meal, 2,990 and 3,172; spray-dried plasma 70\%, 2,673 and 2,730; spray-dried plasma 78\%, 3,027 and 3,704; and erythrocytes, 2,834 and 3,256. All AME and AMEn meal values obtained in the second period were higher than those obtained in the first one.
\end{abstract}

Key Words: broilers, chemical composition, metabolizable energy

\section{Introdução}

$\mathrm{Na}$ formulação de rações, é fundamental conhecer o valor nutritivo dos alimentos. Para isso, devem ser determinadas a composição química, a disponibilidade dos nutrientes e a concentração energética dos alimentos. A energia (produto resultante da transformação dos nutrientes pelo metabolismo animal) presente nos alimentos, o valor energético dos alimentos e as exigências nutricionais em energia das aves têm sido expressos em forma de energia metabolizável aparente (Albino et al., 1992). Os valores de energia metabolizável (EM) dos alimentos são importantes 
no cálculo de rações para aves e sua utilização é essencial para a produtividade e a rentabilidade do setor.

Existem vários métodos para determinar os valores de EM, entre eles, o de coleta total de excretas com pintos de corte, que, apesar de mais utilizado, apresenta alguns contratempos, como a interferência da idade das aves nos valores de energia. As aves mais jovens possuem menor capacidade de digestão e absorção dos nutrientes, visto que o sistema digestivo encontra-se ainda em desenvolvimento, enquanto as mais velhas, com sistema digestivo plenamente desenvolvido, possuem maior tamanho do trato digestivo e maior produção de enzimas e secreções gástricas, daí o melhor aproveitamento dos alimentos.

A composição química dos subprodutos de origem animal é bastante variável. Essas variações podem ser, em parte, explicadas pela forma de processamento empregada, pelo tipo e pela proporção dos materiais utilizados (Penz Jr. et al., 1999).

Objetivou-se determinar a composição química e os valores de energia metabolizável de alguns alimentos protéicos com frangos de corte em duas idades diferentes.

\section{Material e Métodos}

O experimento foi realizado no Setor de Avicultura do Departamento de Zootecnia da Universidade Federal de Viçosa no período de 16/06/2004 a 15/07/2004.

As análises químicas para a determinação da composição química dos alimentos foram realizadas no Laboratório de Nutrição Animal do Departamento de Zootecnia da Universidade Federal de Viçosa, sendo determinados os valores de MS, PB, EE, FB, FDN, FDA, EB, cinzas, Ca e fósforo (P) conforme metodologia descrita por Silva (2002).

Os valores de energia metabolizável aparente (EMA) e aparente corrigida (EMAn) foram determinados utilizando-se o método tradicional de coleta total de excretas em pintos de corte de 21 a 30 e de 41 a 50 dias de idade. As aves foram criadas em círculos de proteção em galpão de alvenaria e receberam ração inicial formulada conforme descrito por Rostagno et al. (2000) até 21 dias de idade, quando, então, foram transferidas para baterias metálicas, dando-se início ao primeiro período experimental. Foram utilizados 396 pintos machos da linhagem Ross no período de 21 a 30 dias de idade (peso médio de 662,89 g), em um delineamento experimental inteiramente casualizado, com dez tratamentos, seis repetições e seis aves por unidade experimental.

Entre os alimentos testados, seis (farelo de algodão, duas farinhas de carne e ossos, farinha de peixe, farinha de vísceras aves com alto teor de gordura e glúten de milho) substituíram em 30\% a ração-referência (Tabela 1) e os outros quatros (dois plasmas sangüíneos, hemácias e concentrado protéico de soja) substituíram em $20 \%$ a raçãoreferência. O período experimental teve duração de dez dias, cinco de adaptação e cinco para coleta total de excretas. As excretas de todas as unidades experimentais foram coletadas em bandejas cobertas com plástico a intervalos de 12 horas para evitar fermentação. O material coletado foi colocado em sacos plásticos e armazenado em congelador até o final do período de coleta. Ao término do experimento, foi determinada a quantidade total de ração consumida por repetição. As excretas foram descongeladas, pesadas e homogeneizadas, sendo retiradas alíquotas, que foram présecas em estufa de ventilação forçada, a $60^{\circ} \mathrm{C}$, por 72 horas, para análises e determinação da MS, da EB e do nitrogênio das rações e das excretas, segundo método descrito por Silva (2002).

Aos 30 dias de idade, as aves foram levadas novamente para o galpão de alvenaria, onde receberam ração para a fase de crescimento, durante dez dias, segundo recomendações de Rostagno et al. (2000).

O segundo período experimental foi iniciado quando as aves completaram 41 dias de idade. Duzentas e sessenta e quatro aves (peso médio de $2.208 \mathrm{~g}$ ) foram distribuídas em um delineamento inteiramente casualizado, com dez tratamentos, seis repetições e quatro aves por unidade experimental, sendo alimentadas com as mesmas rações utilizadas no $1 \underline{0}$ período experimental.

Assim como no primeiro período experimental, foram adotados cinco dias de adaptação e cinco dias de coleta total de excretas. As excretas foram coletadas a intervalos de 12 horas, sendo acondicionadas em sacos plásticos e armazenadas em congelador até o final do período de coleta.

As análises das excretas coletadas no segundo período experimental foram realizadas com os mesmos procedimentos do primeiro período.

As temperaturas média, máxima e mínima nos dois períodos experimentais $\left(24\right.$ e $16^{\circ} \mathrm{C}$, respectivamente) foram registradas diariamente por dois termômetros de máximas e mínimas, ambos distribuídos aleatoriamente dentro da instalação.

Os valores de EMA e EMAn foram determinados por meio das equações descritas por Matterson et al. (1965).

Os dados foram analisados por meio de análise de variância e, para verificar se houve diferença significativada EMA e da EMAn dos alimentos entre as duas idades avaliadas, analisaram-se somente os efeitos da idade dentro de cada tratamento utilizando-se o teste $\mathrm{F}$ a $5 \%$ de probabilidade. 
Tabela 1 - Composição química e valor nutricional da raçãoreferência, na matéria natural

Table 1 - Ingredient and chemical compositions and nutritional value of the reference diet, as-fed basis

\begin{tabular}{|c|c|}
\hline $\begin{array}{l}\text { Ingrediente } \\
\text { Ingredient }\end{array}$ & $\%$ \\
\hline Milho $(7,8 \%$ PB $)$ & 56,35 \\
\hline $\begin{array}{l}\text { Corn }(7.8 \% C P) \\
\text { Farelo de soja ( } 45 \% \text { PB) } \\
\text { Soybean meal }(45 \% C P)\end{array}$ & 35,82 \\
\hline $\begin{array}{l}\text { Soybean meal }(45 \% \text { CP) } \\
\text { Óleo de soja }\end{array}$ & 3,85 \\
\hline $\begin{array}{l}\text { Soybean oil } \\
\text { Fosfato bicálcio }\end{array}$ & 1,82 \\
\hline $\begin{array}{l}\text { Dicalcium phosphate } \\
\text { Calcário } \\
\text { Limestone }\end{array}$ & 0,98 \\
\hline $\begin{array}{l}\text { Sal } \\
\text { Salt }\end{array}$ & 0,46 \\
\hline $\begin{array}{l}\text { Salt } \\
\text { DL-metionina }(99 \%)\end{array}$ & 0,24 \\
\hline $\begin{array}{l}\text { DL-methionine } \\
\text { L-lisina HCL }(98 \%)\end{array}$ & 0,16 \\
\hline $\begin{array}{l}\text { L-lysine } \\
\text { Premix vitamínico }{ }^{1}\end{array}$ & 0,10 \\
\hline $\begin{array}{l}\text { Vitamin supplement } \\
\text { Premix mineral }^{2}\end{array}$ & 0,05 \\
\hline $\begin{array}{l}\text { Mineral supplement } \\
\text { Anticoccidiano (Salinomicina 12\%) } \\
\text { Anticocidial (Sainomicine 12\%) }\end{array}$ & 0,05 \\
\hline $\begin{array}{l}\text { Cloreto de colina } 60 \% \\
\text { Choline chlorine }\end{array}$ & 0,10 \\
\hline Promotor de crescimento (Avilamicina 10\%) & 0,01 \\
\hline $\begin{array}{l}\text { Growth promoter (Avilamicine 10\%) } \\
\text { Antioxidante (BHT) } \\
\text { Antioxidant }\end{array}$ & 0,01 \\
\hline $\begin{array}{l}\text { Composição calculada } \\
\text { Calculated composition }\end{array}$ & 100,00 \\
\hline $\begin{array}{l}\mathrm{PB}(C P)(\%) \\
\mathrm{EM}(M E)(\mathrm{kcal} / \mathrm{kg}) \\
\text { Energia metabolizável determinada }(\mathrm{kcal} / \mathrm{kg})\end{array}$ & $\begin{array}{r}21,00 \\
3.050 \\
3.370\end{array}$ \\
\hline Determined metabolizable energy & \\
\hline $\mathrm{Ca}(\%)$ & 0,960 \\
\hline $\begin{array}{l}\text { P disponível } \\
\text { Available P }(\%)\end{array}$ & 0,450 \\
\hline $\mathrm{Na}(\%)$ & 0,222 \\
\hline Metionina + Cistina (\%) & 0,897 \\
\hline Methionine + Cystine & \\
\hline $\begin{array}{l}\text { Lisina }(\%) \\
\text { Lysine }\end{array}$ & 1,263 \\
\hline
\end{tabular}

${ }^{1}$ Níveis de suplementação vitamínica (Supplementation of vitamin levels): vit. A - 15.000.000 UI; vit. D3 - $1.500 .000 \mathrm{UI}$; vit. E - $15.000 \mathrm{UI}$; vit. B1 $2,0 \mathrm{~g}$; vit. B2 - $4,0 \mathrm{~g}$; vit. B6 - 3,0 g; ác. pantotênico (pantothenic acid) 10,0 g; vit. K3 - 3,0 g; ácido fólico (folic acid) - 1,0 g; ácido nicotínico (nicotinic acid - 25,0 g; vit. B12 - 15.000 mg; e veículo q.s.p. - $1.000 \mathrm{~g}$.

2 Níveis de suplementação mineral (Supplementation of mineral levels): $\mathrm{Mn}-80,0 \mathrm{~g} ; \mathrm{Fe}-80,0 \mathrm{~g} ; \mathrm{Zn}-50,0 \mathrm{~g} ; \mathrm{Cu}-10,0 \mathrm{~g} ; \mathrm{Co}-2,0 \mathrm{~g} ; \mathrm{I}-1,0 \mathrm{~g}$; e veículo q.s.p. - $1.000 \mathrm{~g}$.

\section{Resultados e Discussão}

Quando comparados os dados obtidos (Tabela 2) aos descritos na literatura, observaram-se variações entre os valores de composição química dos alimentos, tanto nas tabelas nacionais (Rostagno et al., 2000; EMBRAPA, 1991) quanto nas internacionais (Blas et al., 2003; NRC, 1994 e
1998). Essas variações podem ser causadas por fatores como a variação existente entre solos e climas, os tipos e tempos de processamento e as condições inadequadas de armazenamento dos alimentos.

Os valores de composição química do farelo de algodão foram semelhantes aos citados por Albino et al. (1982) e Rostagno et al. (2000).

A maior variação nos valores de EE, FB e minerais, em relação às tabelas nacionais, foi observada no farelo de glúten de milho $60 \%$. Os valores obtidos neste trabalho, de modo geral, foram semelhantes aos reportados por Nunes et al. (2004) e Rodrigues et al. (2001).

A soja integral extrusada parcialmente desengordurada apresentou composição semelhante à da soja integral extrusada descrita por Rostagno et al. (2000), porém com valores de EE e de EB inferiores, como esperado, visto que a soja parcialmente desengordurada, após o processo de extrusão, é prensada para retirada de parte do óleo. O concentrado protéico de soja também apresentou valores semelhantes aos descritos por Rostagno et al. (2000), exceto de minerais, que foram superiores.

Os valores de composição química das farinhas de carne e ossos e de peixe tiveram variação significativa quando comparados aos descritos nas tabelas internacionais (Blas et al., 2003; NRC, 1994 e 1998), sendo a maioria dos resultados inferiores. Esses resultados podem ser atribuídos, principalmente, aos diferentes métodos de processamento e às matérias-primas utilizados em outros países (Coelho, 1983). Azevedo (1997) e Vieites et al. (2000), ao avaliarem a composição química e energética de várias farinhas de carne e ossos, também observaram variação entre as farinhas estudadas.

Os plasmas sangüíneos, as hemácias, a farinha de vísceras de aves de alto teor de gordura e a farinha de penas (alimentos menos utilizados na nutrição de aves) também apresentaram grande variação nos valores de composição química e energética em relação à literatura consultada (Albino et al., 1981; Albino et al., 1992; Bellaver et al., 1998; EMBRAPA, 1991; Blas et al., 2003; NRC, 1994; 1998).

Os valores de EMA e de EMAn determinados nas diferentes idades encontram-se na Tabela 3. Os valores de EMA foram superiores aos de EMAn em ambas as idades avaliadas. As aves apresentaram balanço positivo de nitrogênio, caracterizado pela retenção de nitrogênio do alimento. Segundo Shires et al. (1980), as perdas energéticas de origem metabólica e endógena nas excretas apresentam pouca influência nos valores de EMA e EMAn.

Os valores de EMA e EMAn encontrados para o segundo período experimental foram superiores $(\mathrm{P}<0,05)$ aos do primeiro período experimental para os alimentos farelo de 
Tabela 2 - Composição química e valores de energia bruta dos alimentos, expressos na matéria natural ${ }^{1,2}$ Table 2 - Chemical composition and values of gross energy of feedstuffs, as-fed basis ${ }^{1,2}$

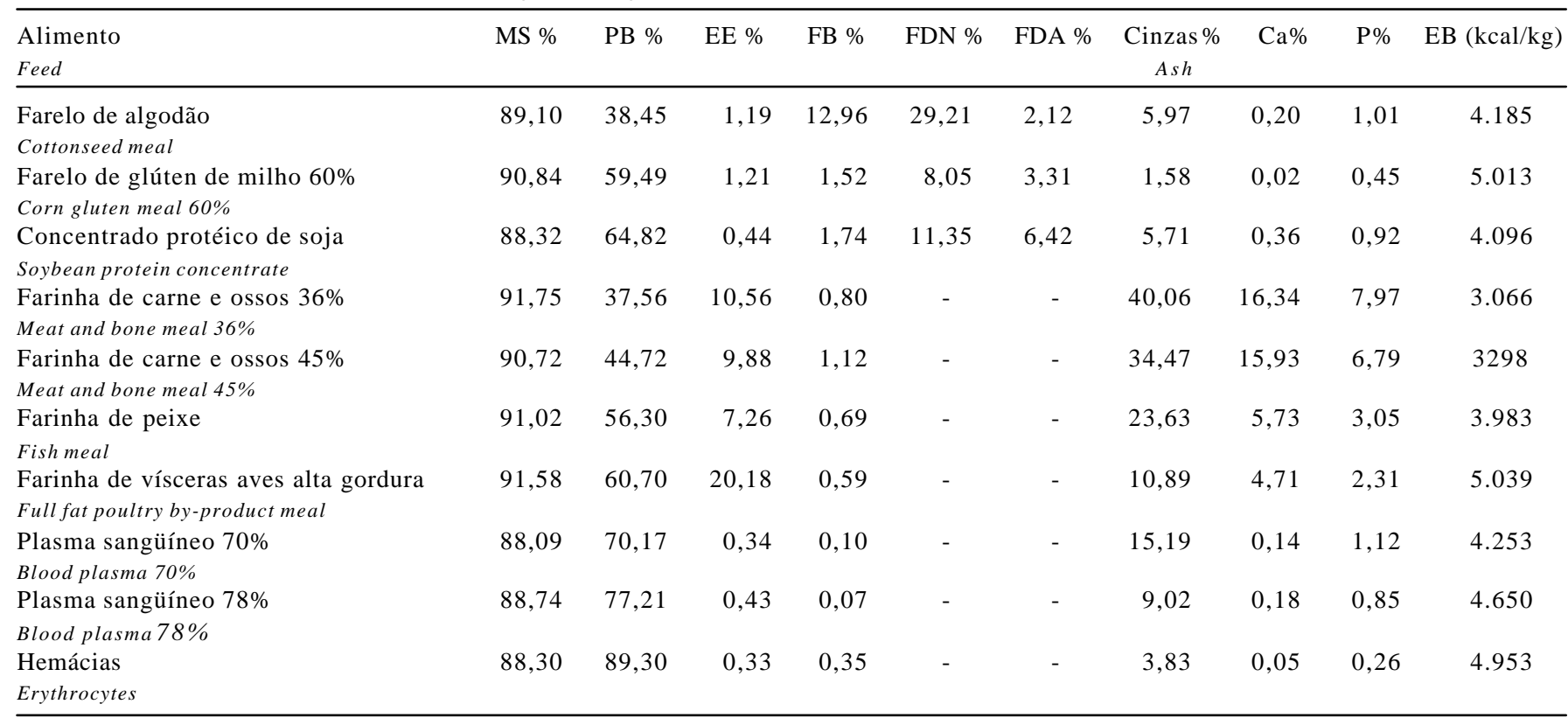

${ }^{1}$ Análises realizadas no Laboratório de Nutrição Animal de Departamento de Zootecnia - UFV.

${ }_{1}$ Analyses were performed at the Animal Nutrition Laboratory of the Animal Science Department - UFV.

Tabela 3 - Valores de energia metabolizável aparente (EMA) e aparente corrigida (EMAn) dos alimentos em função da idade das aves, expressos na matéria natural ${ }^{1}$

Table 3 - Values for apparent metabolizable energy (AME) and apparent metabolizable energy corrected by nitrogen (AMEn) of feeds in function of the age of the poultry, expressed in the natural matter

\begin{tabular}{|c|c|c|c|c|}
\hline \multirow[t]{2}{*}{$\begin{array}{l}\text { Alimento } \\
\text { Feedstuff }\end{array}$} & \multicolumn{2}{|c|}{$\begin{array}{c}\text { EMA }(\mathrm{kcal} / \mathrm{kg}) \\
A M E(k c a l / k g)\end{array}$} & \multicolumn{2}{|c|}{$\begin{array}{c}\text { EMAn }(\mathrm{kcal} / \mathrm{kg}) \\
\text { AMEn }(k c a l / k g)\end{array}$} \\
\hline & $\begin{array}{l}21 \text { a } 30 \text { dias } \\
21 \text { to } 30 \text { days }\end{array}$ & $\begin{array}{l}41 \text { a } 50 \text { dias } \\
41 \text { to } 50 \text { days }\end{array}$ & $\begin{array}{l}21 \text { a } 30 \text { dias } \\
21 \text { to } 30 \text { days }\end{array}$ & $\begin{array}{l}41 \text { a } 50 \text { dias } \\
41 \text { to } 50 \text { days }\end{array}$ \\
\hline Farelo de algodão (Cottonseed meal) & $1.965 \mathrm{a}$ & $2.467 \mathrm{~b}$ & $1.963 \mathrm{~A}$ & $2.461 \mathrm{~B}$ \\
\hline Farelo de glúten de milho $60 \%$ (Corn gluten meal $60 \%$ ) & $3.726 \mathrm{a}$ & $4.138 \mathrm{~b}$ & $3.608 \mathrm{~A}$ & $4.013 \mathrm{~B}$ \\
\hline Concentrado protéico de soja (Soybean protein concentrate) & $2.060 \mathrm{a}$ & $2.159 \mathrm{a}$ & $2.043 \mathrm{~A}$ & $2.155 \mathrm{~A}$ \\
\hline Farinha de carne e ossos $36 \%$ (Meat and bone meal $36 \%$ ) & $1.330 \mathrm{a}$ & $1.712 \mathrm{~b}$ & $1.249 \mathrm{~A}$ & $1.573 \mathrm{~B}$ \\
\hline Farinha de carne e ossos $45 \%$ (Meat and bone meal $45 \%$ ) & $1.418 \mathrm{a}$ & $1.892 b$ & $1.391 \mathrm{~A}$ & $1.766 \mathrm{~B}$ \\
\hline Farinha de peixe (Fish meal) & $3.136 \mathrm{a}$ & $3.183 \mathrm{a}$ & $3.055 \mathrm{~A}$ & $3.077 \mathrm{~A}$ \\
\hline Farinha de vísceras aves alta gordura (Full fat poultry by-product meal) & $3.134 \mathrm{a}$ & $3.297 \mathrm{a}$ & $2.990 \mathrm{~A}$ & $3.172 \mathrm{~A}$ \\
\hline Plasma sangüíneo $70 \%$ (Blood plasma $70 \%$ ) & $3.006 \mathrm{a}$ & $3.170 \mathrm{a}$ & $2.673 \mathrm{~A}$ & $2.730 \mathrm{~A}$ \\
\hline Plasma sangüíneo $78 \%$ (Blood plasma $78 \%$ ) & $3.241 \mathrm{a}$ & $4.043 \mathrm{~b}$ & $3.027 \mathrm{~A}$ & $3.704 \mathrm{~B}$ \\
\hline Hemácias (Erythrocytes) & $2.932 \mathrm{a}$ & $3.390 \mathrm{~b}$ & $2.834 \mathrm{~A}$ & $3.256 \mathrm{~B}$ \\
\hline
\end{tabular}

${ }_{1}^{1}$ Médias seguidas por letras distintas na linha, dentro de cada característica, diferem $(P<0,05)$ pelo teste de $F$.

${ }^{1}$ Means followed by different letters within a row, within each characteristic, differ $(P<0.05)$ by $F$ test.

algodão, farelo de glúten de milho, farinha de carne e ossos $36 \%$ e $45 \%$, plasma sangüíneo $78 \%$ e hemácias.

No período de 21 a 30 dias de idade, os valores de EMA e EMAn para o farelo de algodão foram semelhantes aos citados por Rostagno et al. (2000) e superiores aos encontrados por Albino et al. (1982).

$\mathrm{O}$ farelo de algodão é um alimento fibroso e a diferença $(\mathrm{P}<0,05)$ entre os dois períodos estudados provavelmente está associada ao fato de que aves mais jovens apresentam menor capacidade de digestão e absorção das fibras, pois não possuem o sistema digestivo plenamente desenvolvido.

Para o farelo de glúten de milho, os valores de EMA e de EMAn obtidos no período de 21 a 30 dias de idade foram semelhantes aos citados por Rostagno et al. (2000) e inferiores aos determinados por Fischer Jr. et al. (1998), Nunes et al. (2004) e Rodrigues et al. (2001). O concentrado protéico de soja apresentou valores inferiores aos obtidos por Rostagno et al. (2000) e semelhantes aos relatados porBlas et al.(2003). Para este alimento, a comparação à literaturainternacional 
é mais coerente, pois sua produção não foi realizada no Brasil.

Os valores de EMA e EMAn obtidos nas farinhas de carne e ossos (FCO) no período de 21 a 30 dias de idade foram inferiores aos descritos por Rostagno et al. (2000) e semelhantes aos encontrados por Azevedo (1997) e Vieites et al. (2000) em algumas farinhas. Ao trabalhar com quatro níveis de inclusão de $\mathrm{FCO}(5,10,20$ e 40\%) nas rações-teste, Azevedo (1997) observou diminuição dos valores de EMA à medida que aumentou o nível de inclusão desse alimento nas rações. Possivelmente, o nível de $30 \%$ de FCO utilizado neste trabalho acarretou excesso de íons cálcio no lúmen intestinal das aves, resultando na saponificação da gordura deste alimento, reduzindo sua utilização. Uma das possíveis explicações para os melhores valores encontrados para o período de 41 a 50 dias de idade refere-se ao menor impacto do teor de minerais nesses animais.

Os valores de EMA e EMAn encontrados para a farinha de peixe avaliada no período de 21 a 30 dias de idade foram superiores aos citados por Rostagno et al. (2000) e EMBRAPA (1991) e semelhantes aos obtidos no período de 41 a 50 dias de idade. A matéria-prima utilizada neste alimento, assim como nos demais subprodutos de origem animal, é bastante variada, evidenciando a importância na determinação de padrões para produção.

A farinha de vísceras de aves com alto teor de gordura apresentou valores de EMA e EMAn inferiores aos descritos por Rostagno et al. (2000) e semelhantes aos do resíduo de abatedouro de aves citados por Bellaver et al. (1998), Blas et al. (2003) e NRC (1994). A matéria-prima do resíduo de abatedouro de aves utilizado nesses trabalhos é semelhante à farinha de vísceras de aves de alto teor de gordura. É um alimento com alto teor de gordura e, portanto, rico em energia e com boa composição química.

Os valores de EMA e EMAn dos plasmas sangüíneos e das hemácias obtidos no primeiro período foram semelhantes aos citados por Blas et al.(2003) e, possivelmente, as variações observadas entre as duas idades são decorrentes do alto teor de PB e do tamanho das partículas (muito finas) desses alimentos, o que pode causar irritação à mucosa das aves. As aves mais velhas eliminam de forma mais eficiente este excesso de proteína e seriam menos susceptíveis a esta irritação, aproveitando melhor a energia desses alimentos.

Os valores de EMA e EMAn dos alimentos estudados no período de 41 a 50 dias de idade foram, em média, 12,95\% superiores aos obtidos no período de 21 a 30 dias de idade, evidenciando a necessidade de complementar as tabelas nacionais e internacionais com valores energéticos em diferentes idades para frangos de corte para auxiliar os nutricionistas na elaboração de rações mais eficientes.

\section{Conclusões}

Os valores de EMAn (kcal/kg), na matéria natural, nos períodos de 21 a 30 e de 41 a 50 dias de idade, foram, respectivamente, 1.963 e 2.461 para o farelo de algodão; 3.608 e 4.013 para o glúten de milho; 2.043 e 2.155 para o concentrado protéico de soja; 1.249 e 1.573 para a farinha de carne e ossos 36\%; 1.391 e 1.766 para a farinha de carne e ossos 45\%; 3.055 e 3.077 para a farinha de peixe; 2.990 e 3.172 para a farinha de vísceras de aves de alto teor de gordura; 2.673 e 2.730 para o plasma sangüíneo $70 \% ; 3.027$ e 3.704 para o plasma sangüíneo $78 \%$; e 2.834 e 3.256 para as hemácias.

Todos os alimentos apresentaram valores superiores de EMA e de EMAn no segundo período experimental, indicando que, com o avançar da idade, as aves aproveitam melhor os alimentos.

\section{Literatura Citada}

ALBINO, L.F.T.; ROSTAGNO, H.S.; FONSECA, J.B. et al. Tabela de composição de alimentos concentrados. Valores de composição química e de energia determinados com aves em diferentes idades. Revista da Sociedade Brasileira de Zootecnia, v.10, n.1, p.133-146, 1981.

ALBINO, L.F.T.; FERREIRA, A.S.; FIALHO, E.T. et al. Determinação dos valores de energia metabolizável e matéria seca aparentemente metabolizável de alguns alimentos. Revista da Sociedade Brasileira de Zootecnia, v.11, n.2, p.207$220,1982$.

ALBINO, L.F.T.; ROSTAGNO, H.S.; TAFURI, M.L. Utilização de diferentes sistemas de avaliação energética de alimentos na formulação de rações para frangos de corte. Revista da Sociedade Brasileira de Zootecnia, v.21, n.6, p. 1037-1046, 1992.

AZEVEDO, D.M.S. Fatores que influenciam os valores de energia metabolizável da farinha de carne e ossos para aves. Viçosa, MG: Universidade Federal de Viçosa, 1995. 58p. Dissertação (Mestrado em Zootecnia) - Universidade Federal de Viçosa, 1997.

BELLAVER, C.; PARSONS, C.; EASTER, R.A. Estimates of true amino acid digestibilities in feed ingredients using precisionfeed, cecectomized roosters. Pesquisa Agropecuária Brasileira, v.33, n.5, p.731-736, 1998.

BLAS, C.; MATEOS, G.G.; REBOLAR, P.G. et al. Tablas de composición y valor nutritivo de alimentos para la fabricación de piensos compuestos. 2.ed. Madri: Fundación Española para el Desarrollo de la Nutrición Animal - FEDNA, 2003. 253p.

COELHO, M.G.R. Valores energéticos e de triptofano metabolizável de alimentos para aves, utilizando duas metodologias. Viçosa, MG: Universidade Federal de Viçosa, 1983. 77p. Dissertação (Mestrado em Zootecnia) - Universidade Federal de Viçosa, 1983.

EMPRESA BRASILEIRA DE PESQUISA AGROPECUÁRIA EMBRAPA. Tabela de composição química e valores energéticos de alimentos para suínos e aves. 3.ed. Concórdia: EMBRAPA- Centro Nacional de Pesquisa de Suínos e Aves, 1991. 97p.

FISHER JR., A.A.; ALBINO, L.F.T.; ROSTAGNO, H.S. et al. Determinação dos valores de energia metabolizável de alguns alimentos usados na alimentação de aves. Revista Brasileira de Zootecnia, v.27, n.2, p.314-318, 1998. 
MATTERSON, L.S.; POTTER, L.M.; STUTZ, M.W. et al. The metabolizable energy of feed ingredients for chickens. Storrs: University of Connecticut, Agricultural Experiment Station Research Report, 1965. v.11, 11p.

NATIONAL RESEARCH COUNCIL - NRC. Nutrient requirements of poultry. 9.ed. Washington, D.C.: National Academy of Sciences, 1994. 155p.

NATIONAL RESEARCH COUNCIL - NRC. Nutrient requirements of swine. 3.ed. Washington, D.C.: National Academy of Sciences, 1998. 189p.

NUNES, R.V.; ROSTAGNO, H.S.; NUNES, C.G.V. et al. Coeficiente de digestibilidade e nutrientes digestiveis de alguns alimentos para aves. Revista Brasileira de Ciência Avícola, v.6, p.121$121,2004$.

PENZ JR., A.M.; KESSLER, A.M.; BRUGALLI, I. Novos conceitos de energia para aves. In: SIMPÓSIO INTERNACIONAL SOBRE NUTRIÇÃO DE AVES, Porto Alegre, 1999. Anais... Porto Alegre: Universidade Federal de Porto Alegre, 1999. p.1-24.

RODRIGUES, P.B.; ROSTAGNO, H.S.; ALBINO, L.F.T. Valores energéticos do milheto e subprodutos do milho determinados com frangos de corte e galos adultos. Revista Brasileira de Zootecnia, v.30, n.6, p.1767-1778, 2001.
ROSTAGNO, H.S.; ALBINO, L.F.T; DONZELE, J.L. et al.Tabelas brasileiras para aves e suínos: composição de alimentos e exigências nutricionais. Viçosa, MG: Universidade Federal de Viçosa, 2000. 141p.

SHIRES, A.; ROBBLEE, A.R.; HARDIN, R.T. et al. Effect of the age of chickens on the true metabolizable energy values of feed ingredients. Poultry Science, v.59, n.1, p.396-403, 1980.

SILVA, D.J.; QUEIROZ, A.C. Análise de alimentos (métodos químicos e biológicos). 3.ed. Viçosa, MG: Editora UFV, 2002. $235 \mathrm{p}$.

VIEITES, F.M.; ALBINO, L.F.T.; SOARES, P.R. Valores de energia metabolizável aparente da farinha de carne e ossos para aves. Revista Brasileira de Zootecnia, v.29, n.6, p.2292-2299, 2000. 